\title{
Adolescence and Type 1 Diabetes: Evaluation and Psychological Treatment of a Case with Intellectual Development Disorder
}

\author{
Guillermo S Santibáñez González* \\ Diabetes Unit San Juan de Dios Hospital, Santiago City, Chile
}

*Corresponding author: Guillermo S Santibáñez González, Diabetes Unit San Juan de Dios Hospital, Santiago City, Chile, E-mail: guillermo. santibanez@redsalud.gob.cl

Received: 21 Aug, 2019 | Accepted: 28 Aug, 2019 | Published: 04 Sep, 2019

Citation: Santibáñez GS (2019) Adolescence and Type 1 Diabetes: Evaluation and Psychological Treatment of a Case with Intellectual Development Disorder. J Diab Res Ther 5(2): dx.doi.org/10.16966/2380-5544.146

Copyright: (c) 2019 Santibáñez GS. This is an open-access article distributed under the terms of the Creative Commons Attribution License, which permits unrestricted use, distribution, and reproduction in any medium, provided the original author and source are credited.

\section{Abstract}

The care of adolescents with Type 1 Diabetes is a challenge for pediatric and adult health teams, especially if we find psychological or psychiatric comorbidities in this population. The case of a 14-year-old adolescent with type 1 diabetes and intellectual development disorder who presented problems of adherence to diabetic treatment is described. Psychological evaluation was performed to obtain a cognitive, emotional and relational profile. A 6-month intervention was planned for cognitive stimulation, frustration management and behavioral regulation in the family. The psychological intervention contributed to take a comprehensive look at the problem of adherence, support the adolescent and his family in the process of recovery of diabetic care and improve metabolic control but without achieving the optimal HbA1c value $(<7.5 \%)$.

Keywords: Adolescence; Diabetes; Intellectual development disorder; Adherence problems

\section{Introduction}

Adolescents with type 1 diabetes and intellectual development disorder [1] are a great challenge for families and health professionals who must interact with these young people. The timely psychological evaluation and subsequent intervention proposal is what ensures a solution to the problems of adherence that can be generated in adolescents who present this comorbidity.

\section{Case Report}

Male adolescent who began psychological care at 14 years and 10 months of age. He had type 1 diabetes since he was 5 years old and was regularly monitored in a specialized Pediatric Unit since that time. He was an only child of separated parents and lived with the mother and maternal family (grandparents, aunt and cousin). He was referred to Psychology due to a persistent difficulty in adhering to diabetic selfcare behaviors (mean $\mathrm{HbA} 1 \mathrm{c}$ during the last year=13.0\%).

\section{Family Psychological Interview}

Mother and teenager attended. The mother said that about a year ago she had noticed "rebellious behaviors" associated with the care of his diabetes, noting that the adolescent had missed insulin doses on several occasions, being one so severe that he had a serious decompensation that required hospitalization. She added that the father maintained regular contact with his son through visits on weekends. When asked about other behaviors that would attract her attention, the mother pointed out that the adolescent had had problems with learning and that he attended a common primary school until the fourth grade, being referred to a special need therapist who, after evaluating him, determined serious learning difficulties especially in reading and writing, and suggested his change to a special school where he currently attended. Behavioral problems were also reported in the home, crisis of anger and crying that the mother reported as "tantrums", little autonomy in basic activities such as feeding and dressing. It did achieve personal hygiene. He slept with his mother for "fear of decompensation of his diabetes."

Throughout the interview, the adolescent was inhibited, dependent and discouraged. In agreement with the mother and the subsequent consent of the father, the evaluation started.

\section{Psychological Evaluation of the Adolescent}

Given the background of the case, a cognitive, emotional and relational evaluation (communication with parents and the rest of the family) was suggested.

The cognitive evaluation was carried out with the Wechsler Children's Intelligence Test third edition (WISC-III Chilean version) [2], applicable from 6 years of age to 16 years, 11 months and 30 days of age. This test consists of a series of tasks that explore the verbal and practical performance of the evaluated person to finally deliver a General Intellectual Coefficient and two other specific ones: Verbal Coefficient and Execution Coefficient. 
When applying the test, the adolescent's cognitive profile was deficient in all the coefficients evaluated (Table 1).

Since these results confirmed an Intellectual Deficit, the evaluation was complemented with the DSM5 criteria (1) for Intellectual Development Disorder:

- Deficiencies in intellectual functions, confirmed by clinical evaluation and with standardized and individualized intelligence tests (WISC-III Chilean version). It was fulfilled.

- Impairment of adaptive functioning that limits participation and performance in activities of daily living (home and school). It was fulfilled.

The emotional evaluation was carried out with the Max Lüscher Color Test [3]. This instrument consists in the fact that the evaluated person makes different chromatic choices that account for his internal and external psychological functioning, in this case with a special emphasis on the affective/cognitive regulation of his impulses and aggressiveness due to the cognitive deficit.

Applied the test, the emotional profile of the teenager showed aggressiveness and impulsivity increased with low emotional and cognitive regulation (Figure 1).

The family/relational evaluation was conducted with an in-depth interview with both parents together and then separately. Clinically there was a parental pair worried and committed to the well-being of the adolescent, however, they presented discordant parenting styles that generate ambivalences in the adaptive behavior of the child. The mother maintained a permissive style with occasional limits, adding the difficulty of intrusion of maternal grandparents in the role of the mother's authority, which decreased her influence on the child. The father maintained a more democratic style with clear and precise setting of limits although he tended to experience frustration for the son's behavior that made him inconsistent in his style, in addition he had less frequent contact with the teenager by not living with him.

\section{Psychological Intervention}

An individual intervention was proposed for the adolescent for 6 months with a frequency of two sessions per month. The therapeutic goals were:

- Cognitive stimulation to improve attention, concentration and use of judgment in specific situations.

- Affective and behavioral regulation in order to clarify emotions and impulses, assess concrete consequences of actions and seek alternative behaviors with the mediation of adults.

- Social skills development to generate spaces of respect, kindness and cooperation in the relationship with parents and other significant adults.

Table 1: Cognitive Profile.

\begin{tabular}{|l|c|c|c|}
\hline Evaluated Coefficient & $\begin{array}{c}\text { Normal } \\
\text { Range }\end{array}$ & $\begin{array}{c}\text { Obtained } \\
\text { Range }\end{array}$ & Diagnosis \\
\hline General IQ & $90-110$ & 47 & $\begin{array}{c}\text { Intellectually } \\
\text { Deficient }\end{array}$ \\
\hline Verbal Coefficient & $90-110$ & 46 & $\begin{array}{c}\text { Intellectually } \\
\text { Deficient }\end{array}$ \\
\hline Execution Coefficient & $90-110$ & 60 & $\begin{array}{c}\text { Intellectually } \\
\text { Deficient }\end{array}$ \\
\hline
\end{tabular}

Psychoeducation [4] to both parents together and separately according to the needs of support throughout the intervention with the adolescent. The objectives were:

- Clarify parenting style, its advantages and disadvantages

- Promote agreements between both parents and limit the intrusion of other adults

- Foster positive parental skills [5] (empathy, training, protection, reflection)

\section{Evolution of the Case at 6 Months}

With the collaboration of the parents, the teenager regularly attended his individual sessions. He had a positive response to the intervention demonstrating interest and commitment to the tasks proposed both in the cognitive and emotional areas.

$\mathrm{He}$ participated enthusiastically in the activities of cognitive stimulation, which considered exercises of verbal comprehension, perceptual organization, processing speed and working memory taken from the WISC-III Chilean version. He managed to tolerate his frustration in execution failures which helped regulate his reactions in the school environment. The affective and behavioral regulation had a lower impact on the home due to the limitations of judgment and anticipation of consequences in the adolescent in addition to the deficit of some positive parental skills of the mother, mainly training and reflection. Consequently, she tended to accept the continuous intrusion of her parents in the upbringing which generated a confusion of roles. The father managed to maintain his formative and reflexive role although he generated an inconsistent impact on the adolescent's behavior due to the limited time he shared with his son and his tendency to avoid confrontations with the mother's family. The development of social skills was stimulated throughout all sessions in the relationship with the therapist, applying modeling techniques [6] where the therapist showed the actions and desirable reactions in a context of social interaction. Parents were also trained to apply positive reinforcements [7] to the adolescent's progressive efforts to relate better at home. However, this aspect of the intervention should be a permanent task with the adolescent given its cognitive characteristics.

Both parents responded optimally in assistance and participation with psycho education. The psychological intervention contributed to a decrease in the value of HbAlc (10.8\%) although it did not reach its optimum level $(<7.5 \%)$.

\section{Discussion}

Type 1 diabetes in adolescence could generate a series of conflicts in the process of personality structuring as well as in family dynamics and climate due to the progressive demands and responsibilities that the patient must acquire on his way to adulthood; however, this process can be seriously altered when there is a comorbidity that prevents the correct development of the adolescent. Both the American Diabetes Association (ADA) [8] and the International Society for Pediatric and Adolescent Diabetes (ISPAD) [9] have documented recommendations for adolescent psychosocial care, however, recommendations on neurocognitive functioning describe the need to periodically evaluate cognitive functions that could be affected by poor metabolic control and there are no specific guidelines for the care of adolescents with intellectual disabilities or intellectual development disorder. In this case, the evaluation and diagnosis of a case of intellectual development disorder allowed the timely understanding of the peculiar characteristics of this adolescent with type 1 diabetes and the impact that this condition could have on his adherence to medical treatment. 
Figure 1: Emotional Profile.

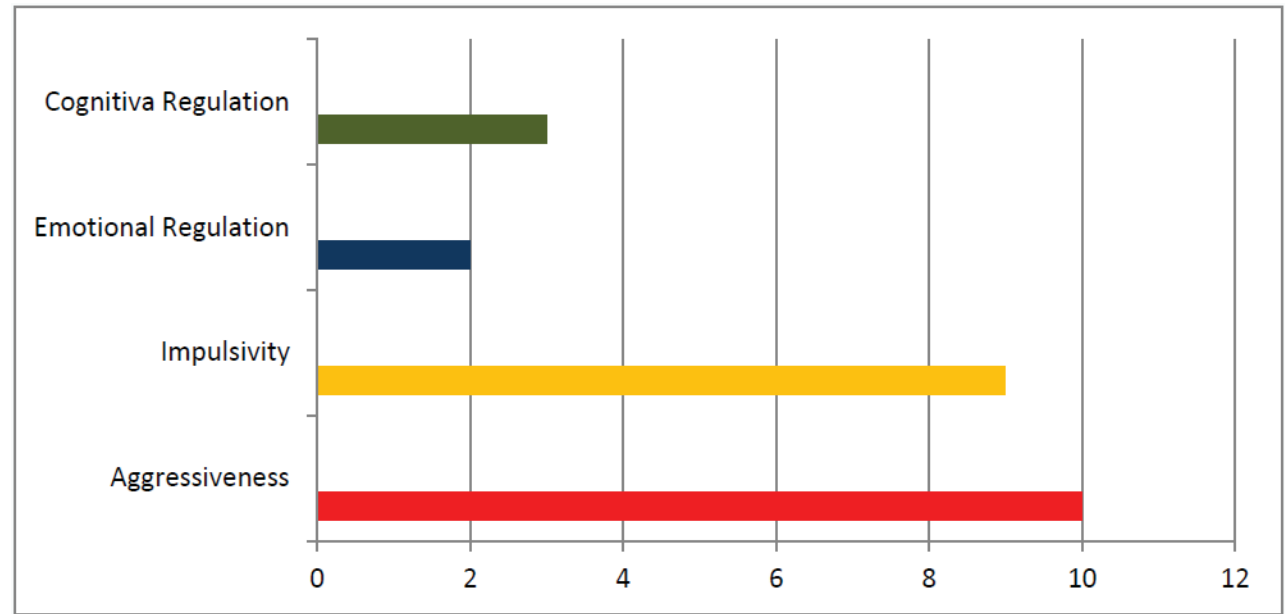

Normal Range $=3-8$

With this diagnosis, a short-term intervention was implemented to facilitate the development of minimal self-care behaviors by the patient and to optimize family support in order to achieve greater commitment to the tasks of treatment and, above all, greater empathy by the health team towards this teenager and his family that came with a history of low adherence.

According to the World Health Organization [10], the evaluation of personal and family psychological factors are a key aspect to understand the failures or delays in proper self-care behaviors and thus to propose educational and/or psychological interventions that allow effective support for the patient and his family.

Although the psychological intervention will not completely solve the problems of adherence or significantly reduce HbAlc levels in an adolescent, it can contribute to a greater commitment to his condition, mobilize family containment and provide health teams with timely information about the psychological peculiarities of a patient that make him unique and that should be at the base of the formulation of a personalized treatment generating collaboration among all health actors instead of resistance and rejection.

\section{Conflict of Interest}

No conflict of interest.

\section{Acknowledgement}

I thank the Biochemistry Dr. Pilar Durruty A, Associate Professor of the Faculty of Medicine of the University of Chile, for her motivation and help in writing this manuscript.

\section{References}

1. Susan E Swedo (2013) Neurodevelopmental Disorders. In: American Psychiatric Association (eds) Diagnostic and statistical manual of mental disorders (DSM- ${ }^{\circledR}$ ). American Psychiatric Pub 33-41.

2. Ramírez V, Rosas R (2007) Standardization of WISC-III in Chile: Description of the Test. Chilean Standardization Standards. Psykhe 16.

3. Longo NV (2001) Lüscher Manual: manual for clinical and nonclinical use of the Lüscher Test. CDO Consultores 23-45.
4. Foelsch PA, Schlüter-Müller S, Odom AE, Arena HT, Borzutzky HA, et al. (2014) Adolescent Identity Treatment: An Integrative Approach for Personality Pathology. (Chapter 5) Springer 67-68.

5. Gómez E, Muñoz M (2015) Positive Parentality Scale Manual. Foundation Ideas for Childhood.

6. Ruiz M, Díaz M, Villalobos A (2012) Modeling and Social Skills Training Techniques. In: Manual of Behavioral Cognitive Intervention Techniques. Desclée De Brouwer, SA.

7. Ruiz M, Díaz M, Villalobos A (2012) Operant Techniques. In: Manual of Behavioral Cognitive Intervention Techniques. Desclée De Brouwer, SA.

8. Young-Hyman D, de Groot M, Hill-Briggs F, González JS, Hood K, et al. (2016) Psychosocial Care for People with Diabetes: A Position Statement of the American Diabetes Association. Psychosocial Research and Care in Diabetes 39: 2126-2140.

9. Cameron FJ, Garvey K, Hood KK, Acerini CL, Codner E (2018) ISPAD Clinical Practice Consensus Guidelines 2018: Diabetes in adolescence. Pediatr Diabetes 19: 250-261.

10. Organisation mondiale de la santé, World Health Organization, UNAIDS (2003) Diabetes. In: Eduardo Sabate, Eduardo Sabaté (eds) Adherence to Long-Terms Therapies: Evidence for Action. World Health Organization 79-82. 